\title{
Macroeconomics Needs Fresh Methodology of Theorization
}

\author{
Bijan Bidabad \\ B.A., M.Sc., Ph.D., Post-Doc. \\ Professor, \\ Economics and Chief Islamic Banking Advisor, \\ Bank Melli, Iran \\ E-mail:bijan@bidabad.com
}

\begin{abstract}
In this paper, we try to analyze the macroeconomic reasoning in different methodological issues. Subsequently, we try to touch some current macroeconomic debates on aggregations, relations, monetary and real sectors analyses. We assess that what we know about the behavior of macroeconomic variables is just our understanding from empiricism, and we have rarely found the laws of linkages among macroeconomic variables. We also conclude that successive theories have an intuitional foundation. It seems that to improve macroeconomic theories and policies, we need to be redirected to basic philosophical thinking about the macroeconomic theoretical foundation and try to rebuild a new concrete base for macroeconomics.
\end{abstract}

Keywords: Macroeconomics, Methodology, Theorization.

\section{Introduction}

Despite the existence of a long history in the realm of macroeconomic theorization, it seems that this important area of economic analysis needs fresh methodological bases. At the micro level of analysis; the characteristics of the phenomenon is more or less under the eyes of the investigator. He actually looks at micro-phenomena as a small specimen that has billions of similars. He can think about the similarities and dissimilarities of micro-phenomena to find some hypothesis or conjectures for explaining their behaviors. But, the same does not exist at the macro level of analysis. At this level, observations are aggregated; samples are not mainly similar; they are not numerous, and constructing hypothesis comes from sense and feeling not scrutinized investigation. Generally, microeconomics is the study of individual economic units and their interactions and is often contrasted with macroeconomics, which is concerned with the behavior of economic aggregates.

\section{Macroeconomic Methodology}

Generally, the macroeconomic methodology uses four main streams of methodological thinking. Let's introduce them as;

- Micro foundation presuppositions

- Meso (micro-macro) foundation presuppositions

- Intuitional foundation presuppositions

- Macro analytic methodology

The first category is often called "neoclassical synthesis" because, in a simple, general equilibrium setting, the framework appears to be consistent with the traditional microeconomic analysis in terms of supply and demand. Behavioral equations at the macro level are obtained by adding up the behavioral equations of individuals whose information about market events is limited to prices.

The second category more or less inspires from some implications of "Robinson Crusoe" type analysis. In mesoeconomics, a representative micro agent is chosen, and her behavior is exaggerated and generalized in such a way that similar corresponding macro behavior is akin to it. For example, in mesoeconomics, a representative firm is used to represent either an industry or the whole economy, depending on the question at hand. 
The third category consists of those theories that come from intuitions and feelings of theoreticians based on their logical reasoning inspired by their findings from general economic, social, and psychological relations and facts among selected aggregate variables.

At the fourth category, theoretician is going to innovate suitable logical tools to explain the relations of aggregates. That is, he tries to build a concrete logical structure from base to roof as similar to the observed phenomena. In contrast to the latter category, he does not try to justify the observations, but his endeavor is to build a specific behavioral model to interpret behavior.

All the above first three categories suffer from certain deficiencies. The major problem with the first category is aggregation from micro to the macro level, which is always tricky. On the other hand, this micro foundation relies on what is generally regarded as the weakest part of micro theory as the tatonnement mechanism. Generalization from micro to macro level as in the second category is again tricky. The majority of problems in these two categories are due to marginal principles. Since this principle, holds at the micro level of analysis but does not hold at the macro level. At the former level, all agents are assumed to act as price takers, and there is no one who can change prices, but at the latter level, the aggregate variables can and should change price level. Despite these, some authors have discussed that the fundamental distinction between macroeconomics and microeconomics is that macroeconomics is an attempt to understand situations of underemployment and excess capacity, while microeconomics is primarily concerned with situations of full utilization of resources (see, Leijonhufvud (I968)). This distinction is well taken, certainly the inspiration for what we today call macroeconomics came from an attempt to understand the prolonged underutilization of resources. Thus, it seems that the aggregated versus disaggregated nature of the study is the fundamental distinction between microeconomics and macroeconomics. In this regard, structuring microeconomic bases for macroeconomic analysis becomes a bit tricky.

The methodology of the third category is highly widespread. Although, it suffers from not having concrete micro or meso foundations, but is not pure of them. Perhaps, it may be claimed that the major contributions to macroeconomics literature belong to this category. Keynes's General Theory of Employment, Interest, and Money (I936) is the most famous milestone in this realm. The analysis based on the feeling and comprehension of the macroeconomic aggregate variables is the major characteristic of this category. Theoreticians in this area try to understand the behavior of aggregates and think to find the interactions howness of them from the past facts. For example, one as Keynes may observe a scatter plot of consumption versus disposable income during a long time horizon. At first glance, observer understands that all points follow each other around a linear straight positively sloped line through the origin at a high degree of closeness. Description of this observation as "Absolute Income Hypothesis" was the inference that Keynes raised. Interpretation of this phenomenon as a theory (consumption function) is free of basic prerequisite logical reasoning. Though, this hypothesis has been shown to be most often true.

The fourth category methodology consists of origins of original thinking in macroeconomic theorization. As an example, we may look at Fisher's The Purchasing Power of Money (I9II). In this book, Fisher uses very simple but concrete logical reasoning to explain the quantity theory of money. His reasoning uses some simple analytical tools as steelyard. Empirical evidence has shown the validity of his theory based on so many evidence for such wide ranges of circumstances. And instances in which prices and quantity of money have moved together are recorded for many centuries of history, for countries in every part of the globe, and for a wide diversity of monetary arrangements.

In subsequent discussions, we are going to touch some of the current macroeconomic discussions briefly, which suffer from not having concrete methodological tools. In this task, we do not survey the literature engaged; since there are valuable references to expose the chronological development of macroeconomic discussions.

\section{Macroeconomic Aggregates}

Generally, the aggregation problem is a scientific task to reduce or combine detailed information when data are too numerous or in too many details to be manageable. The microeconomic theory treats the behavior of optimizing individual agents. The desire to analyze the aggregates of macroeconomics leads to the theories that construct such aggregates from the behavior of individual agents.

Leontief's (1947a, 1947b) theorem states that commodity (or input) aggregate exists if and only if the marginal rate of substitution between any two kinds of commodities (or inputs) is independent of the quantity of other commodities (or inputs) excluded from our commodity (or input) aggregate. That is the marginal rate of substitution between each pair of elements included in and excluded from our aggregate are independents. According to this theorem, we are confronted with many 
difficulties in macroeconomic aggregates (see, F.M. Fisher (I988)). In the case of consumption, if a similar restrictive condition is satisfied for all the aggregates of consumer, then the household's utility function can be written in the aggregate term. If we wish to represent consumer behavior as maximizing the aggregated utility function subject to an aggregated budget constraint, we should have aggregate prices as well as aggregate consumption commodities. Aggregate prices similarly should obey Leontief theorem as well. To construct the aggregate demands of a collection of consumers by horizontal summation of their individual demands causes a set of questions. For example, only aggregate income and not its distribution can influence demand. On the other hand, at given prices, this makes the relative changes of demand to changes of income for all consumers' demand for a given commodity the same constant.

In the case of production, the satisfaction of Leontief condition is again required for aggregation over inputs or outputs. Accordingly, movement of inputs among different firms should leave total output unchanged. This necessarily requires that all firms' production functions be linear in inputs with the same coefficients. Assuming this assumption is highly strong. Even this restrictive assumption will not suffice since there are high differentiations among inputs. That is not all labors are the same and all capital equipment too. On the other side, the linearity of production function implicitly implies a constant return to scale, and this causes to consider small firms equivalent to large ones.

However, we may conclude that the analytical use of macroeconomic aggregates is without sound foundation (see, Fisher (I988) and Sonnenschen (1988)). That is, we cannot treat the consumption and production sides of the economy as a single household or firm. Moreover, we cannot build aggregated variables with similar definitions that we have for microeconomic agents. This latter obstacle actually causes distortion of aggregate variables, which are used in macroeconomic analysis frequently.

\section{Macroeconomic Relations}

In the macroeconomic analysis, we try to investigate the relation among macroeconomic aggregates. Apart from the shortages of aggregates pointed out before, there are lots of paradoxes in macroeconomic relations. Macroeconomists often tend to examine a large domain of economic phenomena by adapting theoretical concepts that had originally been devised for a much narrower range of special issues, especially at the micro level. The discoveries of paradoxical relations derive from the fact that their process of generalization often turns out to be ill-conceived and misleading, if not entirely unwarranted. One of the main sources of disputes among macroeconomists is because of this phenomenon and has made macroeconomics as the most controversial fields of economics. But, science looks for strong theories and behavioral laws to make the man able to forecast and control the states of variables.

\section{Monetary Sector}

There is a huge amount of literature on monetary sector analysis, but among this literature, there are some major questions that have not been responding yet and are of crucial importance as economic methodology viewpoints.

There are many intellectual and philosophical controversies among monetary economists to give a concrete and well-defined foundation for monetary discussions. The philosophical arguments that are milestones for developing theories are well treated but not sufficient in the realm of monetarism. Many monetary variables have not been thoroughly defined yet. Mainly, money itself does not have an exact definition to allow economists to refer to it properly in a theoretical-empirical consistent framework. However, across different structures of different economies, it is concluded that the definition of money should be consistent with what can be used as money in a specific economy and at a specific time. Degree of moneyless and degree of public acceptability of different means as money are other problems that need to be recognized in each economy under consideration. In this regard, the particular content of money may be different from place to place and from time to time. It is discussed that there is no sharp distinction between money and other assets in the real world. Moreover, it is the asset holder's decision that determines what asset types are close substitutes for another and which are not. It is also emphasized that one can define money as what is meant by a sufficiently close substitute for other assets and as far as the definition of money is concerned, the most important issue is the identification and measurement of stable aggregate demand for money function.

Thus, in the context of this more general approach, the correct definition of money becomes a matter of empirical analysis. Here, an important question is arisen, as to what is the theoretical definition of money that is consistent with its real-world application. This is the point that turns the economist attention to the demand motives for money or kinds of assets that are included in the broader definitions of money. On the other hand, it is defined based on the functions that money performs.

Indeterminacies in the definition of money arise from misspecification of the functioning of money in the economy. On the other hand, money is defined commonly as anything that is generally accepted as a means of payment or in final settlement of a 
debt. Thus, this still remains the problem of classification, of enumerating those items that are generally accepted as a means of payment. Acceptability is an attribute possessed by most assets - but in varying degrees. However, for this "concrete" definition of money as means of exchange or store of value, we cannot draw the borderline to distinguish money from other assets that may be physical or non-physical, tangible or non-tangible assets, goods, services and so on. "Abstract" definition of money that thinks of money as a unit of account or measure of value also cannot identify the border of money and other assets. However, in a technologically changing world and continuous improvements in financial systems, drawing such a borderline is not an easy task. The following example shows the reject ability of both concrete and abstract money definitions.

The services that housewives offer their husbands to look after children and managing home affairs are noticeable if we could add them up in national income accounts. However, this is because of problems and shortcomings of national income accounting, but, for these services, no money is allotted, but the wives' services are compensated by other types of services as providing family expenditure and support that their husbands offer their wives. In this particular case, wives' services are exchanged by husbands' services in the absence of money. So, money as a means of exchange is not used, and nothing is stored by money as value. Money is not also used to account the services exchanged or measuring the corresponding value. Therefore, concrete and abstract definitions do not include the phenomenon presented by this example. There are many examples that may be observed which do not satisfy these definitions and the border of money, and other assets remain undefined. Instead, economists have attempted to discuss the functioning of money based on various monetary aggregates. It is also tried that each monetary aggregate has certain characteristics to be consistent for specific issues. However, it is not a good remedy but is actually prevailed.

Now let us consider money as an economic commodity that has its own price and market consequences. If money is working as a commodity, it must have a price. Its equilibrium price should be determined when its demand and supply meet each other in the market. Again another question is arisen, as to what is the "price of money" definition!? There are many works of literature regarding the demand for and supply of money, but in existing theories, there is no coordination between the money demand and supply in the market to determine the price of money. The cornerstone of economic analysis is based on demand and supply analysis, and the main variable in demand and supply functions is price. We always talk about the demand for and supply of money without referring to the "price of money". That is we talk about the amount of quantity exchanged without reference to the price of exchange. Some authors try to interpret inverse of general price level of goods and services as the price of money, but it is only an interpretation of a related variable and replacement of its inverse form instead of the lost "price of money" variable. However, even this interpretation of the "price of money" does not enter into demand and supply analysis of money theoretically. Some other authors think of interest rate as money price. But it is not really true since when money is used for a transaction, no interest is mentioned and when money is used for speculation interest is matter. This means that interest rate as "price of money" is zero for transaction and positive for speculation purposes. Thus, the interest rate is the productivity measure of money source not "price of money". It is by this misunderstanding that we observe the interest rate in the theoretical and empirical formulation of demand for and supply of money. Ignorance of price in demand and supply functions is the same as neglecting the laws of demand and supply (see, Bidabad (20I4))

Monetary transmission mechanism -that is the mechanism of transmission of the effects of the monetary sector onto the real sector is also distorted. The foundation of this mechanism is given by Fisher's equation of exchange. This equation which relates money to the transaction is of the most important in this area, but this equation does not show the relation of the transaction to income and concluding money to income. After the introduction of this important theory, however, other schools of thoughts interpreted income as a scale variable of the transaction and tried to reinterpret velocity of circulation of money only as a variable, which equates nominal income to the stock of money as "income velocity of circulation of money" and so on. These interpretations actually distorted the main proposition of Fisher, which is the most important contribution to monetary economics.

\section{Real Sector}

Let us start the discussion on the aggregate demand and supply as the final conclusions that macroeconomists try to sum up. Generally, as pointed out before, we have not reached a complete methodology to find the economy utility (or welfare) and production functions. Under the highly restrictive assumption, suppose we were able to define them. Even in this case, optimization of global utility or profit of the economy is not possible, because the assumption of rationality does not hold anymore for the global economy. Society is not as rational as an individual. Abolishing of perfect competition is another problem. Comparability of different statics does not establish. The optimization of utility or profit of the global economy is so far from those of individual economic agents, and there is no certainty that even have the same direction. Social benefits can be in the opposite direction of individual benefits. This does not occur rarely, and it is actually a well-known discussion in 
economic literature. By this, it is not possible to maximize the economy's utility function to derive aggregate demand or to maximize the economy profit function to derive marginal cost as the aggregate supply curve. What is used as these functions of aggregate demand and supply are just conjectural curves similar to what we observe at microeconomics as market demand and supply. Sectors of aggregate demand also suffer from not having certain theoretical bases. The main part of aggregate demand is the consumption function. This function should be a demand schedule. And every demand schedules must be functions of prices. This statement is an economic law, not a tautology. This is also true for investment demand function. These functions have deep roots in economic literature, but even no one of them states aggregate consumption or investment demands as functions of prices. In contrast to these sectors, demand for imports and supply of exports that conform to the foreign sector of aggregate demand have been introduced as functions of prices. Other minor sectors of aggregate demand as changes in inventory and depreciation of capital also have the same problem of consumption and investment demands.

Another problem is mathematical aggregation (or summation) of the sectors functions. Since income is equal to production at a macro level, and then the sum of all functions of sectors should add up to income. This condition is satisfied for national income accounts as the sum of sectors expenditures, but it does not hold for sectors of aggregate demand prevailing functions. That is if we sum up consumption function, investment function, government expenditures, export function, and negative of import function, we cannot reach the equation of "income equal to expenditures". On the other hand, the sum of these functions does not reduce to the original mathematical identity of national income.

Other aggregates at the income side of national income accounts as saving, transfer payments, and taxes have a similar problem. The saving function should be directly related to consumption, and thus, it should also be a function of prices. But the only variable that is not observed at saving function is price. The problem of mathematical summation cited before also remains unsolved at this side of national income accounts identity. That is, again, we cannot reach income by mathematical summation of the consumption function, saving function, tax function, and transfer payments function.

Definition of aggregates cannot recognize a definite border among them. We cannot actually distinguish saving from investment. We cannot explain the relation of saving at the monetary sector to saving at the real sector or at national income accounts. That is, we cannot link saving and time deposits at banking sector to saving and investment of real sector. Although saving at banks, saving at national income accounts and investment as sub aggregate of expenditure are all "saving" and are all "investment". Despite this, saving and investment both in monetary and real sectors, lead to the paradox of capital. Capital itself is one of the main controversial variables in macroeconomic analysis. Wealth, the nearest friend of capital, is another problem. These two latter variables have not exact definitions in macroeconomics, and there is no exact criterion to distinguish them. Relating to capital, we cannot distinguish the substitution of old capital equipment by new ones from the depreciation of capital equipment. That is, we cannot draw a border to distinguish capital substitution from capital depreciation.

Relation of foreign exchange to domestic money is another puzzle. We do not know how the exchange rate is determined as a result of the monetary process. We observe a high correlation between domestic money and foreign exchange rates, but we cannot remove the problem of specification error in these relations. This means that we know the existence of such a relationship, but we do not know how it is.

Generally, the relation of variables is based on the empiricism rather that theorism. Empirical relation of inflation and unemployment has been devoted to lots of literature. It is justified for short and long terms, and economists try to interpret why. Dynamism over macroeconomic relations and introducing models as multi-period dynamic relations is just to make unsolved and unidentified problems more complex. In this area, the phenomenon of business cycles and economic fluctuation is of the most important problems. The monetary transmission mechanism is another unsolved problem in this area. We do not have an exact response to the question as to how the monetary sector can affect the real sector, because this mechanism is highly dependent on the interest rate and interest rate is a time-based variable. Thus, all monetary and fiscal policies are determined in a realm of doubts about their effects on the economy.

\section{Conclusion}

Disregarding the how macroeconomic aggregates are constructed and their structural definitional problems, what we know about the behavior of macroeconomic variables is just our understanding from empiricism, and we have rarely found the laws of the inter-relationship among macroeconomic variables. Perhaps it can be said that Fisher's original quantity theory of money is just our main progress at macroeconomics. He tries to express equilibrium rather than going through supply and demand. Other successive theories have an intuitional foundation, as discussed before. Disregarding the definition of agg regate and sub-aggregate variables, national income accounting, and identities among total income and total expenditures and total production is an 
elegant theoretical base for macroeconomic analysis. It seems that to improve macroeconomic theories and policies, we need to redirect researches to basic philosophical thinking about the macroeconomic theoretical foundation and try to rebuild a new concrete base for macroeconomics.

\section{References}

Bidabad, Bijan. [2014], Bijan Bidabad, General monetary equilibrium. Lap Lambert Academic Publishing, Omni Scriptum GmbH \& Co. KG, ISBN: 978-3-659-54045-5, Spring 2014.

Bidabad, Bijan. [20I4], Money-Transaction-Income Process (Quantification of Quantity Theory of Money). Proceeding of the 3rd International Conference on Economics, Political, Law and Fiscal Sciences (EPLS 'I4), World Scientific and Engineering Academy and Society (WSEAS). Transilvania University of Brasov, Brasov, Romania, pp. 213-220, June 2628, 2014 . http://www.bidabad.com/doc/MTV4.pdf http://www.bidabad.com/doc/MTV4.ppt

Bidabad, Bijan. [I99I], Dependence of research methodology on laboratory tools in economics. Methodus, Bulletin of International Network for Economic Method, Vol. 3, No.I, June, I29-30.

Bidabad, Bijan. [1990], Micro-macro analysis of trade and migration, Economic and Management Journal, No. 7, Winter, Islamic Azad University, Tehran, Iran. http://www.bidabad.com/doc/mohajerat-tejarat.pdf

Chrystal, K.A. [1990], (ed.) Monetarism, Vol. I, II; Edward Elgar.

Dean, E. [I965], (ed.); The controversy over quantity theory of money, D.C. Health \& Company, a division of Raytheon education company, Lexington, Massachusetts.

Fisher, I. [I9II], The purchasing power of money, its determination and relation to credit, interest, and crises; assisted by H.G. Brown, reprinted by Augustus M. Kelly bookseller, 1963, New York.

Fisher, D. [1980]. Monetary theory and demand for money, Martin Robertson Pub., Oxford.

Fisher, F.M. [1988] Aggregation problem, The new Palgrave, a dictionary of economics, J. Eatwell, M. Milgate, P. Newman; eds., Macmillan.

Hume, D. [1752]. Of money, in writings on economics, edited by Eugene Rotwein (University of Wisconsin Press, 1970). Reprinted of selected essays from political discourses, I752.

Johnson, H.G. [1979]. (ed.), Selected Essays in Monetary Economics, 2nd impression, George Allen \& Unwin, London.

Keynes, J.M. [1936], General theory of employment, interest, and money, Macmillan, London.

Laidler, D.E.W. [I977]. The demand for money: theories and evidence, 2nd ed., Harper \& Row Inc., New York.

Laidler, D.E.W. [1969]. The definition of money: theoretical and empirical problems, Journal of money, credit and banking, Aug.

Leijonhufvud, A. [1968], On Keynesian economics and the economics of Keynes, New York, Oxford University Press.

Leontief, W.W. [1947a]. A note on the interrelation of subsets of independent variables of a continuous function with continuous first derivatives. Bulletin of American Mathematical Society 53, 343-56.

Leontief, W.W. [1947b], Introduction to a theory of internal structure of functional relationships. Econometrica I5(4), October, 36I-73.

Mayer, T. [1990], (ed.), Monetary theory, Edward Elgar, London.

Muellbauer, J., R. Portes [1978] Macroeconomics models with quantity rationing, The Economic Journal, December.

Newlyn, W.T. [1974], Theory of money, Oxford University Press.

$\mathrm{Ng}$, Yew-Kwang [1986]. Mesoeconomics: a micro-macro analysis, Brighton, U.K., Wheatsheaf.

Pesek, B.P. [1979], Modern bank deposits, and the theory of optimum money, in economic perspectives, an annual survey of economics. M.S. Ballabon (ed.), Baruch College of the city university of New York, Vol. I, Harwood Academic Publishers, Chur, New York.

Patinkin, D. [1965]. Money, interest and prices, an integration of monetary and value theory, 2nd ed., Harper \& Row, New York.

Pierce, D.G., D.M. Shaw [1974]. Monetary economics, theories, evidence, policy; London, Butterworth.

Sonnenschein [1988], Aggregate demand theory, The new Palgrave, a dictionary of economics, J. Eatwell, M. Milgate, P. Newman; eds., Macmillan.

\section{Copyrights}

Copyright for this article is retained by the author(s), with first publication rights granted to the journal. This is an open-access article distributed under the terms and conditions of the Creative Commons Attribution license (http://creativecommons.org/licenses/by/4.0/). 